\title{
PROJECTING FUTURE LOCAL PRECIPITATION AND ITS EXTREMES FOR SWEDEN
}

\author{
DELIANG CHEN ${ }^{1}$, CHRISTINE ACHBERGER ${ }^{1}$, TINGHAI OU ${ }^{1,2}$, ULRIKA POSTGÅRD ${ }^{3}$, \\ ALEXANDER WALTHER $^{1}$ and YAOMING LIAO ${ }^{1,4}$
}

\author{
${ }^{1}$ Regional Climate Group, Department of Earth Sciences, University of Gothenburg, \\ Gothenburg, Sweden \\ ${ }^{2}$ Department of Oceanography, Chonnam National University, Gwangju, Republic of Korea \\ ${ }^{3}$ Swedish Civil Contingencies Agency, Karlstad, Sweden \\ ${ }^{4}$ National Climate Center, China Meteorological Administration, Beijing, China
}

Chen, D., Achberger, C., Ou, T., Postgård, U., Walther, A. and Liao, Y., 2014. Projecting future local precipitation and its extremes for Sweden. Geografiska Annaler: Series A, Physical Geography, ••, ••-••. DOI:10.1111/geoa.12084

\begin{abstract}
A procedure to obtain future local precipitation characteristics focused on extreme conditions has been developed based on a weather generator. The method involves six major steps: (1) the weather generator was calibrated using observed daily precipitation at 220 Swedish stations during 1961-2004; (2) present and future daily precipitation characteristics for the Swedish stations from two global climate models, namely ECHAM5 and HadCM3, were used to calculate weather generator parameters for the present and future climates at global climate model spatial scales; (3) the ratio of the weather generator parameters for the present climate simulated by the global climate models to those calculated for each station falling into the global climate model grid box were computed for all the stations; (4) these ratios were also assumed to be valid in the future climate, that way the future parameters for each station for the global climate model projected future climate could be calculated; (5) using the estimated future parameters of the weather generator, the future daily precipitation at each station could be simulated by the weather generator; (6) the simulated daily precipitation was used to compute eight indices describing mean and extreme precipitation climates. The future mean and extreme precipitation characteristics at the stations under the Second Report on Emission Scenarios A2 scenario were obtained and presented. An overall increasing trend for frequency and intensity of the indices are identified for the majority of the stations studied. The developed downscaling methodology is relatively simple but useful in deriving local precipitation changes, including changes in the precipitation extremes.
\end{abstract}

Key words: weather generator, statistical downscaling, daily precipitation, climate change scenarios, Sweden

\section{Introduction}

The impact of climate change on society due to changes in the atmospheric greenhouse gas (GHG) concentrations is of fundamental importance for future planning and management. Extreme events are part of natural climate variability varying on decadal to multi-decadal time scales. Because of their potentially disastrous effects, many sectors in society, ecosystems and infrastructures are much more sensitive to changes in extremes compared with changes in mean climate. Not surprisingly, much effort in climate research has been devoted to better estimate future climate extremes and to understand driving forces behind extremes (e.g. IPCC 2012).

Climate extremes (including extreme weather or climate events) can be described by various statistics, either in absolute terms such as a variable's maximum or minimum over a certain period of time, as exceedance above or below a threshold or in relative terms expressed as percentiles. Also the impacts such as economic or human losses are used to quantify the severity of an event.

Monitoring of climate extremes observed during the past decades supports an emerging general trend towards more severe precipitation conditions in many parts of the world. The catalogue of climate change indices by the Expert Team on Climate Change Detection Monitoring and Indices (ETCCDMI) profoundly contributed to the objective quantification and characterization of climate variability and change across the globe and to make quantitative comparisons of changes between different geographic regions possible (Karl et al. 1999; Nicholls and Murray 1999; Alexander et al. 2006). For Northern Europe studies show that heavy precipitation has increased in winter in some areas but trends are often insignificant or inconsistent at regional scale, especially in summer (Fowler and Kilsby 2003; Kiktev et al. 2003; Klein Tank and Können 2003; Alexander et al. 2006; Maraun 
et al. 2008; Zolina et al. 2009). Regarding future projected changes until 2100, IPCC (2012) concludes that an increase in days (intensity and frequency) with precipitation greater than the $95^{\text {th }}$ percentile, and days greater than $10 \mathrm{~mm}$ north of $45^{\circ} \mathrm{N}$ in winter is very likely (based on studies of Beniston and Stephenson (2004), Frei et al. (2006), and Kendon et al. (2008)). Studying more specifically Swedish conditions, Achberger and Chen (2006) concluded that a majority of stations show trends towards wetter conditions between 1961 and 2004. Separate trend analysis for the different seasons show that climate mainly gets wetter in winter, spring and summer.

Going beyond the past 60 years, Chen et al. (2015) describe and quantify trends in temperature and precipitation over Europe, including Scandinavia, using a selection of these indices based on the longest daily instrumental records across Europe. Other studies on precipitation extremes in Europe including Nordic countries are Frich et al. (2002), Klein Tank and Können (2003), and Moberg and Jones (2005). Since the number of Scandinavian stations is generally rather limited over such a long period (Moberg et al. 2006; Chen et al. 2014), it is difficult to study spatial variability of rainfall extremes in more detail.

Despite extensive monitoring efforts of recent extremes, improvements in climate modelling or better understanding of the causes of extremes, estimating future precipitation extremes and their geographical pattern is still a challenge (e.g. Ou et al. 2013). Global climate models (GCMs) are to date the only tool to simulate how increased GHG concentrations affect the global climate system. Output from GCMs is, however, spatially still too coarse to realistically and reliably simulate climate conditions at the local scale (e.g. Schoof 2013). Therefore, some type of post-processing or downscaling is needed to translate the coarse GCM output to more relevant information at local or regional scale, most often referred to dynamical and statistical downscaling (e.g. Benestad et al. 2008; Winkler et al. 2011).

In Sweden, dynamically downscaling using a regional climate model (RCM) as well as various statistical downscaling methods have been developed and used in many different applications (e.g. Hellström et al. 2001; Hanssen-Bauer et al. 2005; Chen et al. 2006; Kjellström et al. 2011; Nikulin et al. 2011). Since the spatial resolution of the earlier RCMs (the first Swedish Rossby Centre Regional Atmospheric model (RCA) model had a spatial resolution of $88 \mathrm{~km}$; Rummukainen et al. 2001) it was often argued that this was not fine enough to produce realistic small-scale estimates, especially for the geographically highly varying extremes. In statistical downscaling, however, models can be developed at various spatial scales, even on the site scale. During the past 15 years, the spatial resolution of RCMs have improved considerably and fine-resolved, local information is readily becoming available (Maraun et al. 2010). With this development, one could argue that the need for statistical downscaling is decreasing. However, dynamical downscaling requires high computational expenditure and still has fairly large bias, which makes its applications unpractical. Due to the far smaller computational demand of statistical downscaling, this approach remains flexible and attractive, especially if local projections are to be derived from an ensemble of scenarios (e.g. Chen et al. 2006).

A weather generator (WG) is a stochastic model that can be used to statistically downscale daily weather in the past and future, which provides an effective tool in studying impacts of climate change on a variety of systems, including ecosystem and risk assessment (e.g. Wilks 2010; Jones et al. 2011). WGs can provide additional data when the observed climate record is insufficient with respect to completeness, or spatial coverage or length to allow a reliable estimate of the probability of extreme events (e.g. Wilks and Wilby 1999; Kilsby et al. 2007; Jones et al. 2011). A WG has the advantage to be able to statistically simulate weather over an extensive period using parameters determined from the relatively short history records, thanks to its stochastic nature.

In the early 1960s, the major development of WGs was started. At that time, the research was limited to precipitation simulation and the application was mainly found in hydrology (e.g. Gabriel and Neumann 1962; Bailey 1964). Today, its application reaches to almost every field in assessment of climate impact in conjunction with other models, such as agriculture, soil erosion, land use, and ecological systems. It has also been widely applied in studying impact of extreme events and in risk analysis (e.g. Wilks 1992; Semenov and Barrow 1997; Jones et al. 2011). Current models allow simulation of several variables, including precipitation (occurrence and intensity), temperature (maximum, minimum, dew point, and average), radiation, relative humidity, and wind (speed and direction) (e.g. Richardson and Wright 1984; Semenov et al. 1998; 
Kilsby et al. 2007; Semenov 2008; Liao et al. 2013). Furthermore, they have found wide application in statistical downscaling of GCMs and RCMs to provide information at local scale for climate impact studies (e.g. Hanssen-Bauer et al. 2005; Kilsby et al. 2007; Jones et al. 2009; Maraun et al. 2010).

The overall aim of this work is to develop a statistical method to simulate present and future daily precipitations in Sweden in order to project future changes in local daily precipitation characteristics, especially extreme events. For this task we apply a stochastic weather generator approach (two-state Markov chain model) as suggested by Richardson (1981). Local precipitation scenarios based on two different GCM projections are generated and the results are evaluated with respect to the method's ability to project future local extremes. The paper is structured as follows: the second section provides a detailed description of the data and the methods. The third section shows the results from the application of the method. In the fourth section, sources of uncertainty of the method are discussed, while the fifth section contains a summary and conclusions of the study.

\section{Data and method}

\section{Observed precipitation data}

Within this study, daily precipitation data over Sweden for 1961-2004 from 366 stations across Sweden were used, provided by the Swedish Meteorological and Hydrological Institute. Due to the problem of missing or suspicious records, only stations with less than $10 \%$ missing data were included, resulting in 220 stations. Figure 1 shows the location of stations used in the study together with the grid box layout of the ECHAM5 model (Fig. 1a) and the HadCM3 model (Fig. 1b). Station density varies across the region and is in general lower in the northern half of the country and along the western border to Norway.

The data are corrected for inhomogeneities caused by replacement of observer (for manual stations), relocation of stations, or change of instrument or observation method, but no corrections for rainfall under-catch due to wind exposure, evaporation and wetting are routinely carried out (Engström, E., pers. com. July 3, 2014). Alexandersson (2003) presents maps of corrected annual long-term mean precipitation for the period 1961-1990, estimating rainfall under-catch to $10 \%$ for manual stations and $18 \%$ for automatic stations.
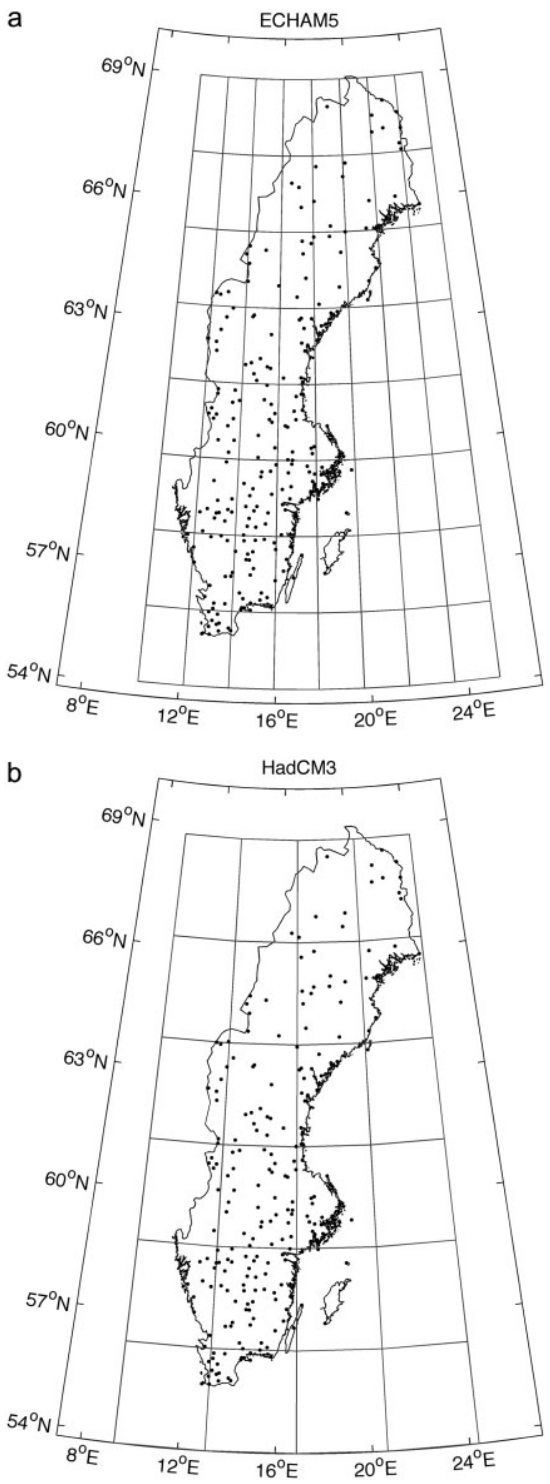

Fig. 1. Location of the 220 precipitation stations in Sweden together with the GCM grid layout for ECHAM5 (a) and HadCM3 (b). All stations record daily precipitation for the period 1961-2004 and have $<10 \%$ missing data.

\section{Precipitation indices}

For this study, climate change indices for precipitation as by the Expert Team on Climate Change Detection Monitoring and Indices (ETCCDMI; Karl et al. 1999; Nicholls and Murray 1999; Alexander et al. 2006) are calculated from daily precipitation observations. Climate change indices serve as a practical and standardized tool to 
Table 1. Precipitation indices used in the study and their hydro-climatological implication.

\begin{tabular}{|c|c|c|}
\hline Index & Description & Implication \\
\hline Nrain & Days per year with precipitation $>0.1 \mathrm{~mm} \mathrm{~d}^{-1}\left(\mathrm{~d} \mathrm{yr}^{-1}\right)$ & precipitation occurrence \\
\hline pint & precipitation intensity (rain per rain day, $\mathrm{mm} \mathrm{d}^{-1}$ ) & daily intensity of rainy days \\
\hline$p q 90$ & 90th percentile of rain day amounts $\left(\mathrm{mm} \mathrm{d}^{-1}\right)$ & intermediate precipitation extremes \\
\hline pxcdd & maximum number of consecutive dry days (d) & measure for risk of dryness \\
\hline pxld & greatest 1-day total rainfall $(\mathrm{mm})$ & measure of short-term extremes \\
\hline$p x 5 d$ & greatest 5-day total rainfall $(\mathrm{mm})$ & measure of longer-term extremes \\
\hline $\operatorname{exc} 25$ & number of days with precipitation $\geq 25 \mathrm{~mm}(\mathrm{~d})$ & rare extreme events \\
\hline $\operatorname{exc} 40$ & number of days with precipitation $\geq 40 \mathrm{~mm}$ (d) & very rare extreme events \\
\hline
\end{tabular}

monitor changes in the statistical properties of the climate focusing on extremes and have been widely applied within the climate research community already. The indices quantify not only rarely occurring temperature and precipitation events, but also the mean climate conditions, providing the general climatological background necessary to put extremes into a broader context.

In this study, eight precipitation indices are used to quantify various properties of past and future local precipitation climate in Sweden, with a focus on occurrence and magnitude of extremes. They partly consist of indices taken from the aforementioned set of climate change indices by Karl et al. (1999) and Nicholls and Murray (1999), and partly of indices, which are widely used and considered useful for Swedish climate. Table 1 lists the definitions of these indices and their implications.

\section{Stochastic rainfall generation}

Weather generators can be used to produce series of different meteorological variables, such as, rainfall, air temperature, wind or sunshine. In this study, however, the focus is on downscaling of precipitation using the Richardson approach (Richardson 1981). Therefore, it is rather a rainfall generator that is developed and presented. Specifically, the NCC/GU-WG (Liao et al. 2004) was applied in this study to each of the 220 sites in Sweden shown in Fig. 1.

The type of WG used here is a two-state Markov chain model as suggested by Richardson (1981). It simulates precipitation occurrence and intensity in two separate steps. In the first step it is determined whether a certain day is dry or wet involving two conditional probabilities: $p 10$ (the probability of a dry day (0) following on a wet day (1)) and p01 (the probability of a wet day following on a dry day). In addition to $p 10$ and $p 01, p 00$ is the probability of a dry day following on a dry day, and p11 is the probability of a wet day following on a wet day (for a detailed description, see Wilks 2010). In all, the two-state Markov chain uses four conditional probabilities, also called transition probabilities. These four transition probabilities were derived from the daily precipitation observations from 1961 to 2004 individually for each of the 220 sites. In addition, since these parameters vary over the course of the year, $p 01, p 11, p 10$ and $p 00$ were calculated separately for each of the 12 calendar months.

The precipitation amounts for wet days are determined in the second step using a random number generator. To ensure that the simulated precipitation intensities have the same statistical properties as the observed ones, the randomly generated precipitation has to be taken from a distribution resembling the observed precipitation frequency. Typically, the frequency distribution of daily precipitation is strongly "skewed" to the left, which implies that there exist a large number of days with relatively small precipitation amounts and a small fraction of days with larger amounts. One distribution function that is often used to describe the empirical frequency distribution of daily precipitation is the Gamma distribution with shape parameter $\alpha$ and the scale parameter $\beta$ :

$$
f(x)=\frac{(x / \beta)^{\alpha-1} \exp (-x / \beta)}{\beta \Gamma(\alpha)} \quad x, \alpha, \beta>0
$$

The shape parameter indicates the skewness of the distribution whereas the scale parameter is related to the total precipitation amount. Clearly, the skewness of the distribution decreases with increasing $\alpha$ when $\beta$ is kept constant, while the growing $\beta$ moves the distribution "to the right" on the $x$-axis when keeping $\alpha$ constant. In general, larger $\alpha$ and $\beta$ imply stronger extremes given that the other parameter is kept constant. 
Table 2. GCMs used in this study. The spatial resolution and the time period of the control run representing today's climate conditions and the scenario simulations for the future are also given.

\begin{tabular}{lcc}
\hline Climate model & Spatial resolution & Model run \\
\hline ECHAM 5 & & Control run 1961-2000 \\
$\begin{array}{l}\text { Max-Planck-Institut für } \\
\text { Meteorologie, Hamburg }\end{array}$ & $1.8^{\circ}$ lon $\times 1.8^{\circ}$ lat & Scenario run (SRES A2) \\
& & $2046-2065,2081-2100$ \\
HadCM3 & & Control run 1961-1989 \\
Hadley Centre, Bracknell, UK & $3.75^{\circ}$ lon $\times 2.5^{\circ}$ lat & Scenario run (SRES A2) \\
& & $2070-2099$ \\
\hline
\end{tabular}

The Gamma parameters and transition probabilities derived from Swedish precipitation observations vary from site to site and over the course of the year. Therefore, they were estimated individually for each station and month of the year.

When simulating daily precipitation, in the first step it is determined whether a certain day is wet or dry based on the monthly transition probabilities. If a day is determined as a wet day, the precipitation amount for this day is simulated by means of the parameters of the Gamma distribution:

$R=\left[-\frac{R N 1^{\frac{1}{\alpha}}}{R N 1^{\frac{1}{\alpha}}+R N 2^{\frac{1}{1-\alpha}}} \times \ln (R N 3)-\ln (R N 4)\right] \times \beta$

where $R$ is the precipitation amount, and $R N 1$, $R N 2, \quad R N 3$ and $R N 4$ are random generated numbers.

\section{GCM climate change scenarios}

Information regarding future large-scale climate conditions is obtained from climate change scenarios provided from GCMs. In this study, daily precipitation data simulated by the ECHAM5 and HadCM3 GCMs were used to derive the WG parameters from the simulations of past and future precipitation conditions at the observational sites. In Table 2, information about the spatial resolution of the GCMs and the time period of the simulation runs are given. From each GCM, both a control run representing today's climate and a scenario run representing future climate conditions are used. The latter are based on A2 emission storylines based on the IPCC Second Report on Emission Scenarios (SRES) (Nakicenovic et al. 2000).

Due to differences in the spatial resolution of the GCMs, the number of the grid boxes covering
Sweden and their location differ considerably between ECHAM5 and HadCM3. Figure 1 shows the location of the GCM grid boxes over Sweden. Here, the significantly lower spatial resolution of the HadCM3 model is obvious.

\section{Downscaling of GCM scenarios by scaling the $W G$ parameters}

To simulate future precipitation conditions at the stations, the parameters of the WG representing future climate must be determined. One way to obtain these parameters is to modify the observed WG parameters by factors corresponding to the ratios of the future climate to that of present climate based on GCM results. This approach is followed here and described in Maraun et al. (2010) and Wilks (2010). It corresponds to some extent to the well known delta change (DC) approach (Hay et al. 2000), since only changes at the GCM grid scale are considered. In its original application, however, $D C$ is used to perturb an observed data series with a projected future climate change (involving the calculation of long-term mean changes (between scenario and control and runs) on a monthly or seasonal basis and adding these mean changes to the observed data series (e.g. Graham et al. 2007; Yang et al. 2010). In this study, however, $D C$ is not applied to a time series but to the observed WG parameters. These modified parameters then represent the precipitation conditions of the future climate. The next step is to obtain local parameters from those at the GCM grid scale. By applying the same changes of the parameters for a given GCM grid to all the stations within the grid, a new set of the future WG parameters for all the stations was created.

Following this procedure, daily precipitation data for each GCM grid box over Sweden containing at least one precipitation station have been 
extracted, for both the control and the scenario run. Please note that this approach assumes that the changes for stations within the same grid are the same. Given that WG parameters are smoother than the spatial variation of precipitation itself (e.g. Semenov and Brooks 1999), this assumption is considered reasonable. Using these time series of simulated daily precipitation, the transition probabilities and the parameters of the Gamma distribution were derived in the same way as from station observations. For each GCM this resulted in two sets of WG parameters for each grid box, one for the control run and one for the scenario run. As for station precipitation, the WG parameters were calculated separately for each calendar month. Then, in the next step, for each station and each month, the ratios $R$ were calculated between the WG parameters from the GCM control runs and the observations:

$$
R=W G_{-} o b s / W G_{-} G C M_{\text {control }} .
$$

In all, this resulted in a set of 72 ratios per station (6 WG parameters $\times 12$ months).

Applying ratios of changed to present climate conditions corresponds both to a downscaling in time and in space (Wilks 2010). Monthly or seasonal climate changes taken from model simulation runs are translated into daily statistics through the Gamma parameters and the transition probabilities. Spatial downscaling from area average to the station scale is realized since the climate change ratio at the model scale is applied to the station-specific WG parameters. This implies that relative changes at the model grid scale proportionally translate to changes at smaller scales (Wilks 2010). Of course, since the numbers of stations in all grids are different and a minimum of one is allowed, the "grid scale" changes may be reduced to smaller scale changes.

\section{Future local precipitation and changes in the indices}

With the new set of WG parameters for the changed climate, the future precipitation was simulated at each station. One hundred years of daily precipitation were simulated with the ECHAM5 (HadCM3) model, representing the climate conditions for the period 2081-2100 (2070-2099). Although the ECHAM5 (HadCM3) time slice only covers 20 (30) years, the WG simulated local series for a period of 100 years in order to achieve higher statistical confidence in the simulated precipitation series. This is especially important when the simulations are used to derive statistics about relatively rare events, that is, extremes.

All precipitation indices listed in Table 1 were calculated from the simulated series at each of the 220 stations in exactly the same ways as were done for the observations. Then, the differences between the observation-based indices and the WG-simulation-based indices were calculated at each station, both as annual and seasonal means. The difference in the indices is used to quantify the magnitude of change in precipitation climate at the local scale.

\section{Results}

\section{Performance of the precipitation generator}

In this section, we compare the simulated precipitation results against observations to assess the quality of the simulations. Since the simulated precipitation series are based on a random number generator, the real temporal evolution of daily precipitation is lost in a simulation. Therefore, comparisons between observations and simulations must rely on the statistical properties of observed and simulated daily series. For this purpose, four indices are selected, pint, Nrain, pxld and p99 (the last one is selected instead of $p 90$ to better evaluate the performance for extreme events). These indices were derived from the simulated 100 years and compared with the corresponding observed statistics for 1961-2004. The scatter plots in Fig. 2 compare annual indices from observations and simulations. Each dot corresponds to one station. For Nrain, the simulations slightly but systematically overestimate the number of rain days, while the simulated extreme indices pxld and $p 99$ are underestimated at almost all stations. The best agreement is achieved for pint.

\section{Annual changes}

Figure 3 shows the geographical distribution of the changes in the eight indices. In general, the simulations suggest a change towards wetter climate conditions at the majority of the stations. The magnitude of the changes and their geographical distribution depend on the GCM used. Both models suggest similar changes in Nrain regarding geographical distribution and magnitude. Pint and $P 90$ will increase at all stations independently of the GCM used, but according to the HadCM3-based simulations, the number of stations with an increase in pint (P90) exceeding $2 \mathrm{~mm} \mathrm{~d}^{-1}(3.9 \mathrm{~mm})$ is larger 
a

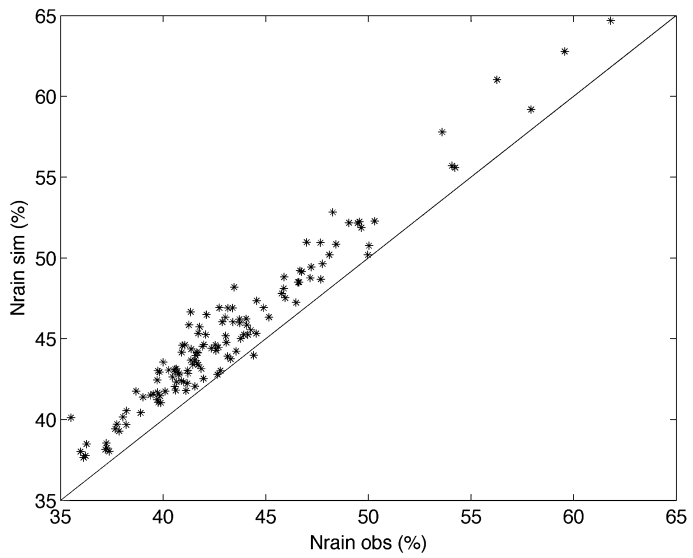

C

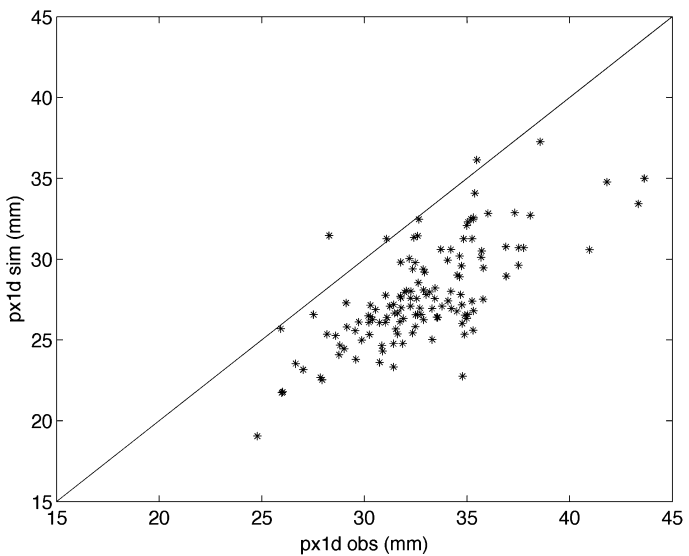

b

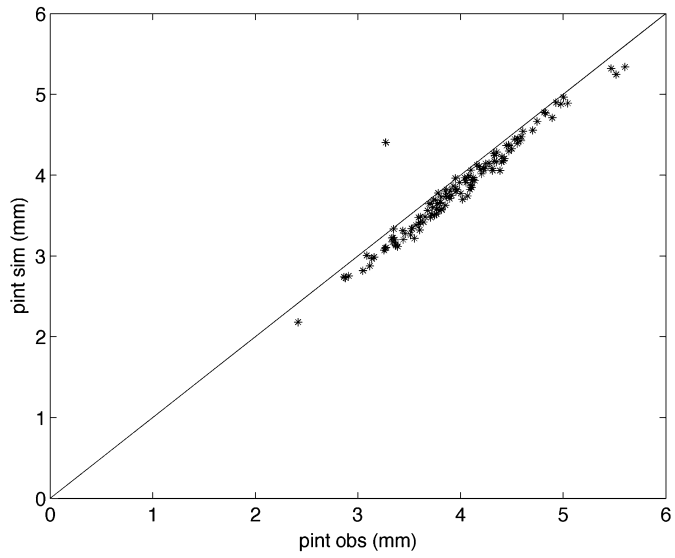

d

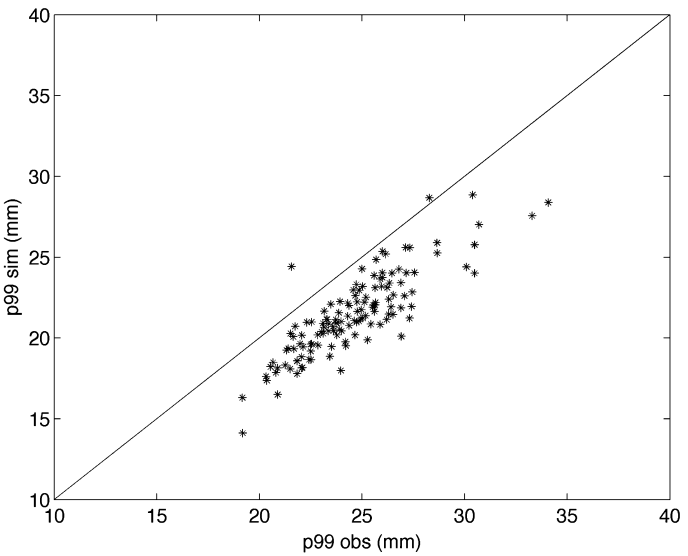

Fig. 2. Evaluation of observations and simulations based selected precipitation indices: (a) Nrain [day], (b) pint [mm $\mathrm{d}^{-1}$ ], (c) pxld $[\mathrm{mm}]$, and (d) p99 [mm]. The evaluation is done on an annual scale, each symbol corresponds to one station.

compared with the ECHAM5-based simulations. Depending on GCM, the patterns of changes in pxld and $p x 5 d$ vary. Furthermore, exc 25 would generally increase as well as exc 40, though only according to HadCM3 (simulations based on ECHAM5 suggest a decrease in exc40 at around $50 \%$ of the stations).

Regarding pxcdd, the results differ as the HadCM3 simulations suggest an increase at almost all the stations, while the ECHAM5-based simulations propose a decrease in $p x c d d$ at many stations.

\section{Seasonal changes}

This section presents changes separately for winter (December, January, February), spring (March, April, May), summer (June, July, August) and autumn (September, October, November).
The statistics of countrywide seasonal changes are summarized in Fig. 4. The length of the bars indicates the fraction of stations (in \%) with positive and negative changes in the seasonal precipitation indices, while different colors give the magnitude of the changes (given in the unit of the index). Generally, all projected future precipitation indices except Nrain and pxcdd point toward wetter conditions at the majority of all the stations and in all the seasons. This is in line with the positive changes at the annual scale. The magnitude of the changes varies depending on season, region and GCM used. Compared with the changes in the other indices, the magnitude and the sign of the changes in Nrain depend to a larger extent on the season. The changes are spatially more homogeneous. In winter, the frequency of wet days increases in almost all parts of Sweden 

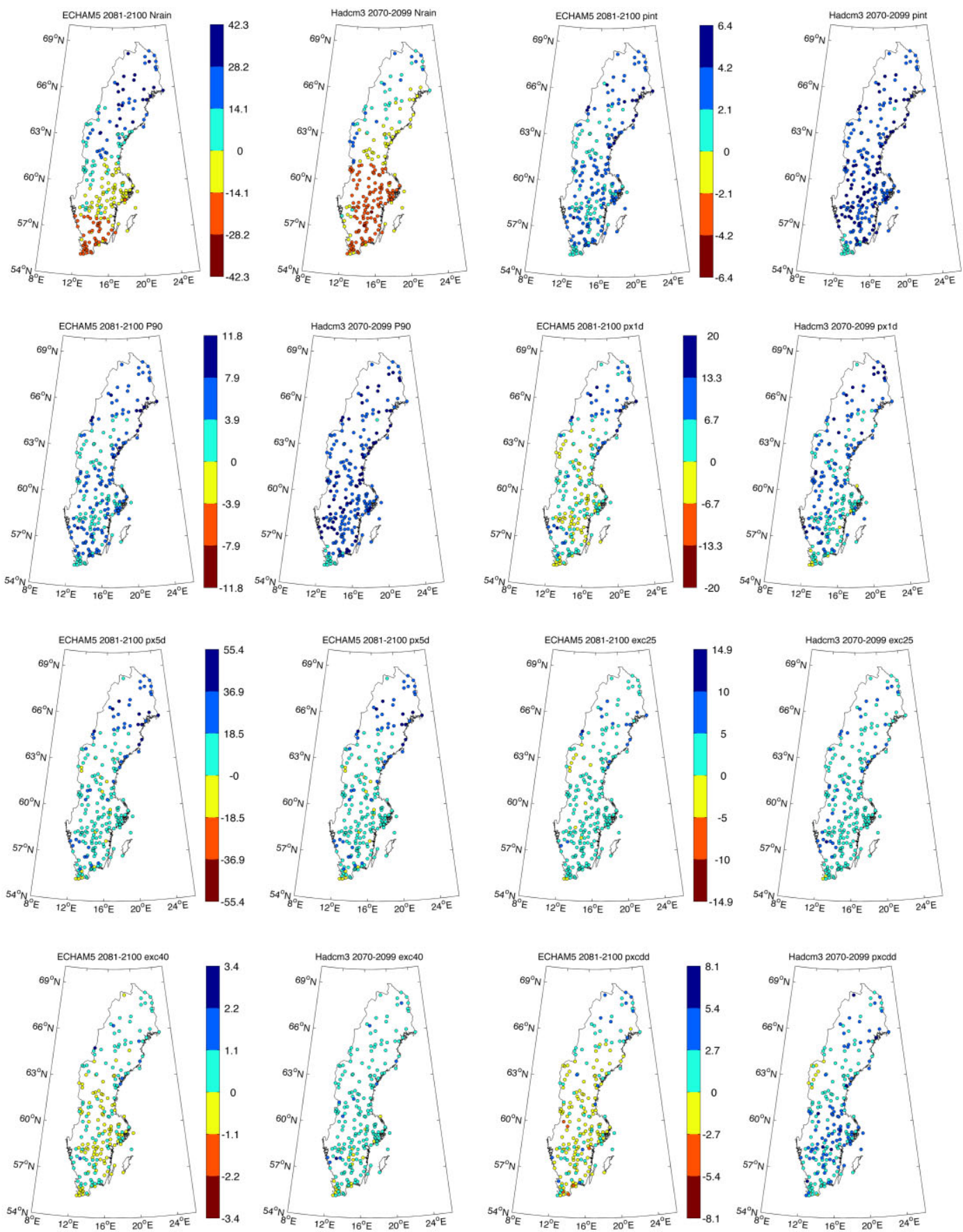

Fig. 3. Annual changes at 220 stations in Sweden derived from WG simulations based on the ECHAM5 scenario run for the years 2081 to 2100 and the HadCM3 scenario run for the years 2070 to 2099 in Nrain [d], pint [mm d ${ }^{-1}$ ], p90 [mm], pxld [mm], px5d [mm $5 \mathrm{~d}^{-1}$, and $\operatorname{exc} 25$ [d]. 

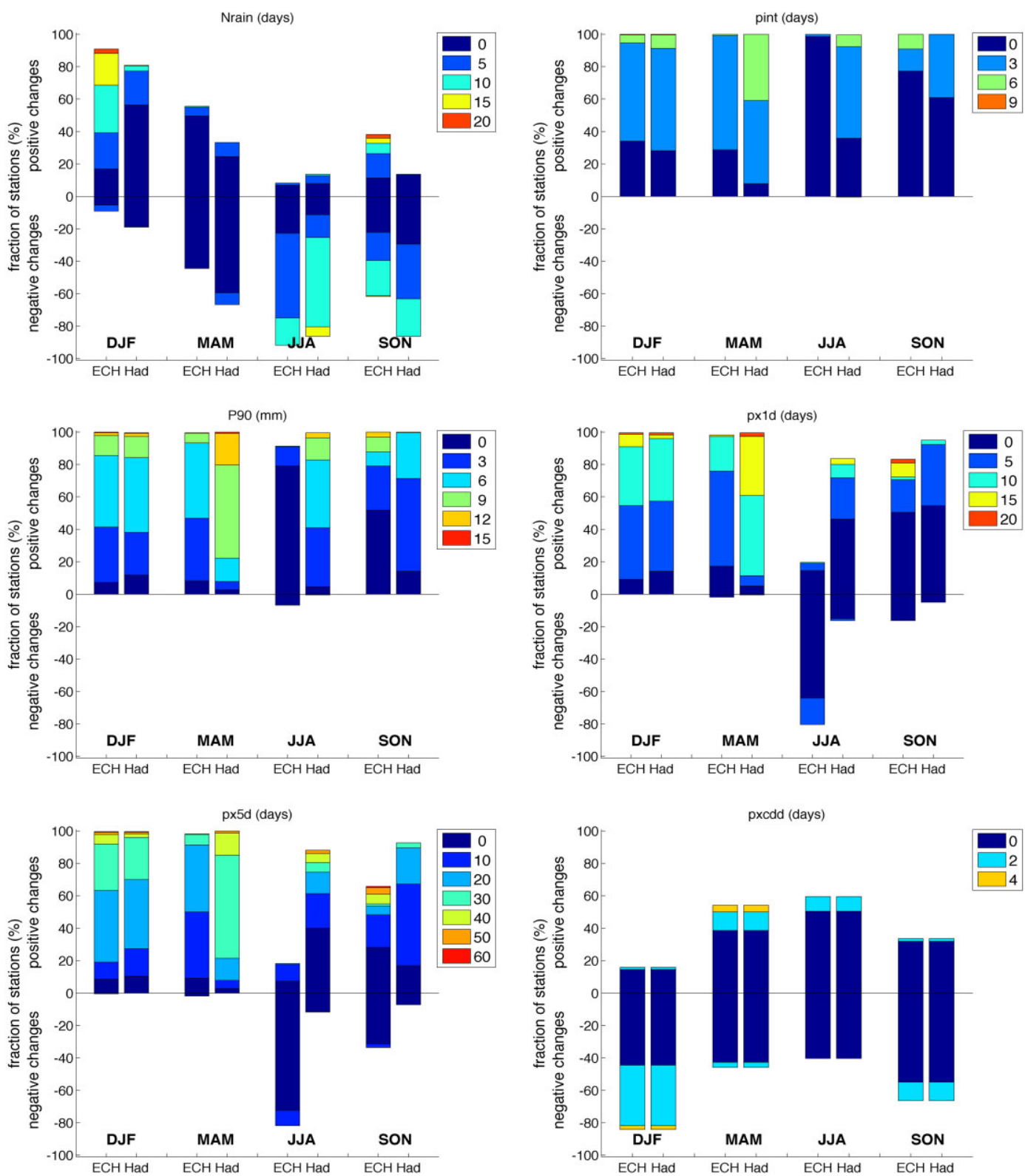

Fig. 4. Fraction of stations (\%) with positive, zero or negative changes in the seasonal precipitation indices derived from WG simulations based on the ECHAM5 scenario run for the years 2081 to 2100 and the HadCM3 scenario runs 2070-2099. The various indices are shown in individual panels.

as suggested by all local scenarios. Towards spring, large parts of southern and central Sweden experience a slight decrease in Nrain; the remaining regions are characterized by a slight increase. In summer, the frequency of wet days drops everywhere except in the northernmost (ECHAM5) and north-western (HadCM3) parts of Sweden. The decrease is especially pronounced in southern Sweden. In autumn, fewer wet days are expected in the south-east according to the ECHAM5-based scenarios. The HadCM3-based simulations suggest a decrease everywhere except in the north-west of 
Sweden. Regarding the indices pint and $p 90$, the local scenarios based on both GCMs produce very similar results, suggesting higher precipitation intensities on rainy days and increased moderate extremes at all stations (very few exceptions occur) in all seasons.

Changes in pxld and $p x 5 d$ are mainly towards stronger intensities at the majority of the stations in spring and winter. However, according to the ECHAM5-based simulations, the maximum oneday and five-day amounts decrease at many stations in southern and central Sweden in summer and autumn. The majority of stations will experience a slight increase in the number of days exceeding $25 \mathrm{~mm} \mathrm{~d}^{-1}$ according to the HadCM3-based local scenarios in all seasons. In winter, however, many stations located in northern Sweden will not experience any change. Index exc25 also slightly increases in winter and spring in the ECHAM5based simulations, whereas exc25 in southern Sweden decreases at many stations in summer. In autumn many stations in southern Sweden are without any change. For the strongest extremes, exc 40 , a rather heterogeneous picture emerges with positive, negative and zero changes occurring in all seasons. Especially the ECHAM5-based simulations estimate at many stations either a drop in the number of days exceeding $40 \mathrm{~mm}$ or zero change in winter, spring and autumn. According to HadCM3, exc 40 increases at a large number of the stations in spring, summer and autumn, while exc40 remains unchanged at many stations in winter. For pxcdd, positive as well as negative changes occur in all seasons both in the HadCM3- and the ECHAM5based simulations. Especially the ECHAM-based local scenarios suggest a decrease in the number of consecutive dry days in autumn and winter; a rise in pxcdd occurs mainly in summer at stations located in southern Sweden. According to the local scenarios using HadCM3, pxcdd mainly increases in all seasons except in winter when the fraction of stations with negative changes is relatively high.

In general, HadCM3-based simulations tend to project wetter conditions in the future. These scenarios partly produce larger changes and wetter conditions for a higher fraction of stations compared with the simulations using ECHAM5 (e.g. pint, $p 90, p x 1 d$ and $p x 5 d$ ). In the ECHAM5-based local scenarios, there is a relatively high fraction of stations with negative changes in summer in pxld, px5d and exc25 and in all seasons for pxcdd. Both GCMs produce rather similar results for Nrain, pint and $p 90$.

\section{Sources of uncertainties}

The success of simulating future daily precipitation at the local scale is dependent on several factors, such as, how well the parameters estimated to calibrate the models correspond to observed precipitation conditions (i.e. frequency distribution); how well extremes are simulated (e.g. rare events); the quality of the GCM used to derive future changes in the WG parameters; if the emission scenarios are realistic; and if the assumptions used in the downscaling are valid. Each of these points may introduce uncertainties in the simulated precipitation series. While it is impossible at this stage to put numbers on the various sources of uncertainties, they can at least be discussed qualitatively.

Regarding the estimation of the Gamma parameters, either the "moment method" or the "maximum-likelihood method" (MLE) is usually used. According to Wilks (2006), the first approach is more simple but also more inefficient, partly since not all of the distribution information is used and the sample moments may differ from the moments of the distribution. Furthermore, there is a risk of incorrect results in cases when the shape parameter is very low. For these reasons, MLE was considered as the statistically more reliable method and was applied here. Referring to Watterson (2005), MLE however tends to underestimate extremes, suggesting the preferred use of the moment method when extremes are to be derived from WG simulations.

Therefore, we tested here to what degree the choice of parameter estimation method influences the estimation of rainfall extremes (as represented by $p 90$ and $p 99$ ). For all the stations, the parameters were estimated from the complete data series using both approaches. Then, $p 90$ and $p 99$ were derived from both estimations and for all the stations and compared with the rainfall intensities of p90 and p99 derived directly from the observations. Compared with the direct estimation from the observations, the moment method underestimates $p 90$ up to $10 \%$ and overestimates $p 99$ up to $10 \%$. MLE, however, overestimates both p90 (up to $10 \%$ ) and $p 99$ up to $45 \%$. Regarding how these differences might influence the estimation of future precipitation changes, we assume that the choice of parameter estimation method has a comparable effect on the estimation of the parameters derived from the GCM simulations. This means that the magnitude of the delta change in the parameters derived from the scenario simulations should not 
be considerably influenced by the choice of the methods.

A possible way of improving the simulation of extremes is to divide the distribution into a "normal" part covering the main rainfall range and an "extreme" part for larger intensities, and applying different distribution functions to these. As an example, Vrac and Naveau (2007) propose a probability mixture model based on the Gamma and Generalized Pareto distributions, where the latter distribution aims to better model the tail. Another approach is presented by Yang et al. (2010), applying distribution-based scaling to correct biased output from regional climate modeling. For this purpose the precipitation distribution was divided into two partitions separated by the 95th percentile. In a further development of the rainfall generator, it would be interesting to investigate to what extent improvements can be achieved by implementing one of the outlined methods.

A major concern in all studies involving data from GCMs is the question, to what degree are the simulations reliable and realistic? A range of different circumstances introduce uncertainties into the model results. Generally, all climate models simplify reality since it is impossible to completely simulate the extremely complicated climate system. Another problem is the restricted spatial resolution in the model, dividing the atmosphere, the land surface and the oceans into a large number of model grid boxes of a certain size. Currently the typical size of a GCM box ranges between $1.2^{\circ}$ lat $\times 1.2^{\circ}$ lon and $3.75^{\circ}$ lat $\times 3.75^{\circ}$ lon. Grid boxes of this size imply a very coarse representation of the properties of the Earth's surface and the processes in the system. Further, variations of weather and climate within one grid box are not modeled explicitly. Since many important processes in the atmosphere, for instance generation of convective precipitation or cloud formation, take place at spatial scales much smaller than the grid boxes, most climate models need to apply parameterizations to include these important subgrid-scale processes in a simplified way. These are just a few examples of factors influencing results from climate models (a more comprehensive discussion can be found in Randall et al. (2007)). Despite all these uncertainties, today's GCMs are able to realistically simulate large-scale features of the recent climate and past climate. Furthermore, they are considered to provide credible estimates of future climate changes at continental or larger scales (Randall et al. 2007).
Regardless of the GCM reliability, projections of the future climate change are dependent on the emission scenarios used to describe the anthropogenic forcing of the climate system. Today, it is impossible to know in detail how GHG emissions will develop in the future since they are highly dependent on demographic, technological and economic developments. Instead, scenarios are created as alternative images of how the future might look and are useful tools to analyze how various driving forces may influence future emission levels. These scenarios cover a wide range of realistic assumptions regarding global population growth, economic and technological development. As a consequence, scenarios are to some extent uncertain, even based on the most plausible assumptions. Usually, GCMs are run with several (or two rather different) emission scenarios to simulate a large part of possible future climate changes.

Finally, there are uncertainties associated with the downscaling procedure. Here, the GCM scenarios are downscaled by scaling the GCM-derived WG parameters to the specific sites using the relationship between the WG parameters representative of an area of the size of a GCM grid box and the WG parameter(s) of the individual site(s) located within this grid box. In a strict sense, such a relationship between the local scale (i.e. the station sites) and the GCM grid box scale is only valid for that period of time for which the relationship was established. A fundamental assumption in statistical downscaling relies on the idea that an empirically established relationship between the two scales is valid even in the future (IPCC 2001), that is, assuming stationarity. Whether this is true or not is impossible to test, as there are no "observations" for the future. One way to check the plausibility of this assumption, however, is to divide the period with observations into several shorter records for which the relationships are found individually. If these relationships are close to each other one can conclude that the relation between scales is stable over time. This does not prove that the assumption is valid in the future, but gives a hint about the variability in the relationship.

\section{Summary and conclusions}

This work describes a procedure to use a WG to create future daily precipitation series at the local scale for Sweden. Simulations of the future precipitation climate for 220 meteorological stations in Sweden were carried out, for which synoptic 
observations existed for the period 1961 to 2004. The large-scale climate change signal for the simulations of the future local precipitation climate were taken from two GCMs, ECHAM5 and HadCM3. One important objective of the work was to quantify future precipitation extremes, which was done by means of selected indices quantifying extreme intensities and frequencies. These indices were derived from the WG simulations of future local precipitation. A large part of the work therefore focuses on these indices, and their changes on an annual scale and across seasons.

The local precipitation scenarios based on the two GCMs show a general change towards increased precipitation intensity across Sweden on an annual scale and in different seasons. In parallel with the decrease in the number of wet days (Nrain) on annual scale, daily precipitation intensity (pint) increases and there is a clear trend towards stronger extremes in the future. However, the magnitude of the changes depends on the index used. Deviations from this general picture emerge depending on GCM and season. Large-scale changes in future precipitation conditions, as estimated from the difference between the GCM scenario and control runs, are manifested by changes in the parameters of the Gamma distribution and the four transition probabilities. Changes in the Gamma parameters indicate an overall increase in precipitation intensity. By means of the sitespecific WG models, this change is translated to the local scale.

Specifically, the following conclusions can be drawn from this study. The local precipitation scenarios based on HadCM3 and ECHAM5 show that the Swedish precipitation climate, on an annual and seasonal scale, would generally become wetter in the future. The magnitude of the change and its geographical distribution varies with index, season and the GCM used for the WG simulation.

The frequency of wet days (Nrain) decreases at many stations on an annual scale. In winter, Nrain increases almost everywhere, in summer, Nrain drops everywhere except in northernmost Sweden (ECHAM5) and in north-west Sweden (HadCM3). Daily precipitation intensities (pint) together with moderate extremes $(p 90)$ increase at all stations on an annual and seasonal scale. The local scenarios based on both GCMs give very similar results.

The one-day $(p x I d)$ and five-day $(p x 5 d)$ maximum precipitation amounts increase at the majority of stations on an annual scale as well as in spring and winter. There is a difference in the magnitude of change depending on the GCM used. Heavy precipitation events $(\operatorname{exc} 25$, exc40) on an annual scale increase at most stations.

Seasonal changes in exc 25 and exc 40 vary with GCM. According to HadCM3, exc25 increases at most stations in all seasons, exc40 in spring, summer, and autumn (exc40). The ECHAM5based simulations estimate either a drop in exc40 or no change in winter, spring and autumn for many stations. The annual and seasonal changes in the number of consecutive dry days ( $p x c d d$ ) vary with GCMs. Especially the ECHAM-based scenarios suggest a decrease in pxcdd in autumn and winter, while a rise in pxcdd occurs in summer at stations in southern Sweden. Using HadCM3, pxcdd increases at the majority of all the stations in all seasons.

The local scenarios based on HadCM3 often give a larger change (wetter conditions) than the ECHAM5-based scenarios.

\section{Acknowledgement}

This study has been supported by the Swedish Civil Contingencies Agency and Swedish Science Council through grants to Deliang Chen. This work is also a contribution to the strategic research programs of BECC and MERGE at University of Gothenburg.

Deliang Chen, Department of Earth Sciences, University of Gothenburg, Box 460, 40530 Gothenburg, Sweden

E-mail: deliang@gvc.gu.se.

Christine Achberger, Tinghai Ou, Alexander Walther, Yiaoming Liao, Department of Earth Sciences, University of Gothenburg, Box 460, 40530 Gothenburg, Sweden

Tinghai Ou, Department of Oceanography, Chonnam National University, 77 Yongbong-ro, Buk-Gu, Gwangju 500-757, Republic of Korea

Ulrika Postgård, Swedish Civil Contingencies Agency, 651 81 Karlstad, Sweden

Yiaoming Liao, National Climate Center, China Meteorological Administration, No. 46, Zhongguancun South Street, Haidian District, Beijing, China

\section{References}

Achberger, C. and Chen, D., 2006. Trend of extreme precipitation in Sweden and Norway during 1961-2004. Research Report C72, ISSN 1400-383X, Earth Sciences Centre, Göteborg University, Gothenburg, Sweden, 58 pp. 
Alexander, L.V., Zhang, X., Peterson, T.C., Caesar, J., Gleason, B., Klein-Tank, A.M.G., Haylock, M., Collins, D., Trewin, B., Rahimzadeh, F., Tagipour, A., Ambenje, P., Kumar, K.R., Revadekar, J. and Griffiths, G., 2006. Global observed changes in daily climate extremes of temperature and precipitation. Journal of Geophysical Research, 111, D05109. doi:10.1029/2005JD006290

Alexandersson, H., 2003. Korrektion av nederbörd enligt enkel klimatologisk metodik [Correction of precipitation observations using a simple method]. SMHI Report [SMHI (Swedish meteorological and hydrological institute) Report], 111, Norrköping, [in Swedish].

Bailey, N.T.J., 1964. The Elements of Stochastic Processes. Wiley, New York.

Benestad, R., Hanssen-Bauer, I. and Chen, D., 2008. Empirical-statistical Downscaling. World Scientific Publishing, Singapore, $300 \mathrm{p}$.

Beniston, M. and Stephenson, D.B., 2004. Extreme climatic events and their evolution under changing climatic conditions. Global and Planetary Change, 44, 1-9. doi:10.1016/j.gloplacha.2004.06.001

Chen, D., Achberger, C., Räisänen, J. and Hellström, C., 2006. Using statistical downscaling to quantify the GCM-related uncertainty in regional climate change scenarios: a case study of Swedish precipitation. Advances in Atmospheric Sciences, 23, 54-60. doi.org/10.1007/ s00376-006-0006-5

Chen, D., Walther, A., Moberg, A., Jones, P.D., Jacobeit, J. and Lister, D., 2015. European Trend Atlas of Extreme Temperature and Precipitation Records. To be published by Springer, Dordrecht Heidelberg New York London, doi: 10.1007/978-94-017-9312-4, 178 p.

Fowler, H.J. and Kilsby, C.G., 2003. Regional frequency analysis of United Kingdom extreme rainfall from 19612000. International Journal of Climatology, 23, 1313 1334. doi:10.1002/joc.943

Frei, C., Schöll, R., Fukutome, S., Schmidli, J. and Vidale, P.L., 2006. Future change of precipitation extremes in Europe: Intercomparison of scenarios from regional climate models. Journal of Geophysical Research: Atmospheres, 111, D06105.

Frich, P., Alexander, L.V., Della-Marta, P., Gleason, P., Haylock, M., Klein-Tank, A. and Peterson, T., 2002. Observed coherent changes in climatic extremes during the second half of the 20th century. Climate Research, 19, 193-212. doi:10.3354/cr019193

Gabriel, R. and Neumann, J.A., 1962. Markov chain model for daily rainfall occurrence in Tel Aviv Israel. Quarterly Journal of Royal Meteorological Society, 88, 90-95.

Graham, L.P., Hagemann, S., Jaun, S. and Beniston, M., 2007. On interpreting hydrological change from regional climate models. Climatic Change, 81, 97-122.

Hanssen-Bauer, I., Achberger, C., Benestad, R., Chen, D. and Førland, E., 2005. Statistical downscaling of climate scenarios over Scandinavia: a review. Climate Research, 29, 255-268. doi:10.3354/cr029255

Hay, L.E., Wilby, R.L. and Leavesley, G.H., 2000. A comparison of delta change and downscaled GCM scenarios for three mounfainous basins in the United States. JAWRA Journal of the American Water Resources Association, 36, 387-397.

Hellström, C., Chen, D., Achberger, C., and Räisänen, J., 2001. Comparison of climate change scenarios for
Sweden based on statistical and dynamical downscaling of monthly precipitation. Climate Research, 19, 45-55. doi.org/10.3354/cr019045

IPCC (Intergovernmental Panel on Climate Change), 2001. Climate Change 2001: The Scientific Basis. Contribution of Working Group I to the Third Assessment Report of the Intergovernmental Panel on Climate Change [Houghton, J.T., Ding, Y., Griggs, D.J., Noguer, N., van der Linden, P.J., Xiaosu, D., Maskell, K. and Johnson, C.A. (eds)]. Cambridge University Press, Cambridge, $881 \mathrm{p}$.

IPCC (Intergovernmental Panel on Climate Change), 2012. Managing the Risks of Extreme Events and Disasters to Advance Climate Change Adaptation. A Special Report of Working Groups I and II of the Intergovernmental Panel on Climate Change [Field, C.B., Barros, V., Stocker, T.F., Qin, D., Dokken, D.J., Ebi, K.L., Mastrandrea, M.D., Mach, K.J., Plattner, G.-K., Allen, S.K., Tignor, M. and Midgley, P.M. (eds)]. Cambridge University Press, Cambridge, UK and New York, USA, $582 \mathrm{p}$.

Jones, P.D., Kilsby, C.G., Harpham, C., Glenis, V. and Burton, A., 2009. UK Climate Projections science report: projections of future daily climate for the UK from the Weather Generator. UK Climate Projections science report. University of Newcastle, UK.

Jones, P.D., Harpham C., Goodess, C.M., and Kilsby, C.G., 2011 Perturbing a weather generator using change factors derived from regional climate model simulations. Nonlinear Processes in Geophysics, 18, 503-511. doi:10.5194/npg-18-503-2011

Karl, T.R., Nicholls, N. and Ghazi, A., 1999. CLIVAR/ GCOS/WMO workshop on indices and indicators for climate extremes: workshop summary. Climatic Change, 42, 3-7. doi:10.1023/A:1005491526870

Kendon, E.J., Rowell, D.P., Jones, R.G. and Buonomo, E., 2008. Robustness of future changes in local precipitation extremes. J Climate, 21, 4280-4297.

Kiktev, D., Sexton, D.M.H., Alexander, L. and Folland, C.K., 2003. Comparison of modeled and observed trends in indices of daily climate extremes. J Climate, 16, 3560 3571.

Kilsby, C.G., Jones, P.D., Burton, A., Ford, A.C., and Fowler, H.J., Harpham, C., James, P., Smith, A. and Wilby, R.L., 2007. A daily weather generator for use in climate change studies. Environ. Model. Software, 22, 1705-1719.

Kjellström, E., Nikulin, G., Hansson, U., Strandberg, G. and Ullerstig, A., 2011. 21st century changes in the European climate: uncertainties derived from an ensemble of regional climate model simulations. Tellus, 63A, 24-40. doi.org/10.3402/tellusa.v63i1.15767

Klein Tank, A.M.G. and Können, G.P., 2003. Trends in indices in of daily temperature and precipitation extremes in Europe, 1946-1999. Journal of Climate, 16, 3665-3680. doi.org.ezproxy.ub.gu.se/10.1175/15200442(2003)016\%3C3665:TIIODT\%3E2.0.CO;2

Liao, Y., Chen, D. and Xie, Y. 2013. Spatial variability of the parameters of the Chinese stochastic weather generator for daily non-precipitation variables simulation in China. Acta Meteorologica Sinica, 71, 1103-1114. doi:10.11676/qxxb2013.089 [in Chinese with English abstract] 
Liao Y., Zhang, Q. and Chen, D., 2004. Stochastic modeling of daily precipitation in China. Journal of Geographical Sciences, 14, 417-426. doi:10.1007/BF02837485

Maraun D., Osborn, T.J. and Gillett, N.P., 2008. United Kingdom daily precipitation intensity: improved early data, error estimates and an update from 2000 to 2006. International Journal of Climatology, 28 (6), 833-842. doi.org/10.1002/joc. 1672

Maraun, D., Wetterhall, F., Ireson, A.M., Chandler, R.E., Kendon, E.J., Widmann, M., Brienen, S., Rust, H.W., Sauter, T., Themeß1, M., Venema, V.K.C., Chun, K.P., Goodess, C.M., Jones, R.G., Onof, C., Vrac, M. and Thiele-Eich, I., 2010. Precipitation downscaling under climate change: recent developments to bridge the gap between dynamical models and the end user. Review of Geophysics, 48, RG3003. doi:10.1029/ 2009RG000314

Moberg, A. and Jones, P.D., 2005. Trends in indices for extremes in daily temperature and precipitation in central and Western Europe, 1901-99. International Journal of Climatology, 25, 1149-1171. doi:10.1002/joc .1163

Moberg, A., Jones, P.D., Lister, D., Walther, A., Brunet, M., Jacobeit, J., Saladie, O., Sigro, J., Aguilar, E., Della-Marta, P., Luterbacher, J., Yiou, P., Alexander, L.V., Chen, D., Klein Tank, A.M.G., Alexandersson, H., Almarza, C., Auer, I., Barriendos, M., Begert, M., Bergström, H., Böhm, R., Butler, J., Caesar, J., Drebs, A., Founda, D., Gerstengarbe, F.-W., Giusi, M., Jónsson, T., Maugeri, M., Österle, H., Pandzic, K., Petrakis, M., Srnec, L., Tolasz, R., Tuomenvirta, H., Werner, P.C., Linderholm, H., Philipp, A., Wanner, H. and Xoplaki, E., 2006. Indices for daily temperature and precipitation extremes in Europe analysed for the period 1901-2000. Journal of Geophysical Research, 111, D22106. doi:10.1029/2006JD007103

Nakicenovic, N. et al., 2000. Special Report on Emissions Scenarios: A Special Report of Working Group III of the Intergovernmental Panel on Climate Change, Cambridge University Press, Cambridge, UK, 599 p. (http:// www.grida.no/climate/ipcc/emission/index.htm)

Nicholls, N. and Murray, W., 1999. Workshop on Indices and Indicators for climate extremes, Asheville, NC, USA, 3-6 June 1999 Breakout Group B: Precipitation. Climatic Change, 42, 23-29. doi:10.1023/A:1005495627778

Nikulin, G., Kjellström, E., Hansson, U., Strandberg, G. and Ullerstig, A., 2011. Evaluation and future projections of temperature, precipitation and wind extremes over Europe in an ensemble of regional climate simulations. Tellus, 63A, 41-55. doi.org/10.1111/j.1600-0870 .2010.00466.x

Ou, T., Chen, D., Linderholm, H.W. and Jeong, J.-H. 2013. Evaluation of global climate models in simulating extreme precipitation in China. Tellus A, 65, 19799. doi.org/10.3402/tellusa.v65i0.19799

Randall, D.A., Wood, R.A., Bony, S., Colman, R., Fichefet, T., Fyfe, J., Kattsov, V., Pitman, A., Shukla, J., Srinivasan, J., Stouffer, R.J., Sumi, A. and Taylor, K.E., 2007. Climate models and their evaluation. In: Climate Change 2007: The Physical Science Basis. Contribution of Working Group I to the Fourth Assessment Report of the Intergovernmental Panel on Climate Change [Solomon, S., Qin, D., Manning, M., Chen, Z., Marquis,
M., Averyt, K.B., Tignor, M. and Miller, H.L. (eds)]. Cambridge University Press, Cambridge, UK and New York, USA. 589-662.

Richardson, C.W., 1981. Stochastic simulation of daily precipitation, temperature, and solar radiation. Water Resources Research, 17, 182-190. doi:10.1029/ WR017i001p00182

Richardson, C.W. and Wright, D.A., 1984. WGEN: a model for generating daily weather variables. US Department of Agriculture, Agricultural Research Service, ARS-8, $83 \mathrm{p}$.

Rummukainen, M., Räisänen, J., Bringfelt, B., Ullerstig, A., Omstedt, A., Willén, U., Hansson, U. and Jones, C., 2001. A regional climate model for northern Europe: model description and results from the downscaling of two GCM control simulations. Climate Dynamics, 17, 339-359. doi.org/10.1007/s003820000109

Schoof, J.T., 2013. Statistical downscaling in climatology. Geography Compass, 7, 249-265.

Semenov, M.A., 2008. Simulation of extreme weather events by a stochastic weather generator. Climate Research, 35, 203-212. doi:10.3354/cr00731

Semenov, M.A. and Barrow, E.M., 1997. Use of a stochastic weather generator in the development of climate change scenarios. Climatic Change, 35, 397-414. doi:10.1023/ A: 1005342632279

Semenov, M.A. and Brooks, R.J., 1999. Spatial interpolation of the LARS-WG stochastic weather generator in Great Britain. Climate Research, 11, 137-148. doi.org/10.3354/ cr011137

Semenov, M.A., Brooks, R.J., Barrow, E.M. and Richardson, C.W., 1998. Comparison of the WGEN and LARS-WG stochastic weather generators for diverse climates. Climate Research, 10, 95-107. doi.org/10.3354/ cr010095

Vrac, M. and Naveau, P., 2007. Stochastic downscaling of precipitation: From dry events to heavy rainfalls. Water Resour Res, 43, W07402.

Watterson, I.G., 2005. Simulated changes due to global warming in the variability of precipitation, and their interpretation using a gamma-distributed stochastic model. Advances in Water Resources, 28, 1368-1381. doi:10.1016/j.advwatres.2004.11.016

Wilks, D.S., 1992. Adapting stochastic weather generation algorithms for climate change studies. Climatic Change, 22, 67-84. doi.org/10.1007/BF00143344

Wilks, D.S., 2006. Statistical Methods in the Atmospheric Sciences. Academic Press, London, 627 p.

Wilks, D.S., 2010. Use of stochastic weathergenerators for precipitation downscaling. Wiley Interdisciplinary Reviews: Climate Change, 1, 898-907.

Wilks, D.S. and Wilby, R.L., 1999. The weather generation game: a review of stochastic weather models. Progress in Physical Geography, 23, 329-357. doi:10.1177/ 030913339902300302

Winkler, J.A., Guentchev, G.S., Liszewska, M., Perdinan and Tan, P.-N., 2011. Climate scenario development and applications for local/regional climate change impact assessments: An overview for the non-climate scientist. Geography Compass, 5, 301-328.

Yang, W., Andréasson, J., Graham, L.P., Olsson, J., Rosberg, J. and Wetterhall, F., 2010. Distribution-based scaling to improve usability of regional climate model projections 
PROJECTING FUTURE LOCAL PRECIPITATION AND ITS EXTREMES FOR SWEDEN

for hydrological climate change impacts studies. Hydrology Research, 41, 211-229. doi:10.2166/ nh. 2010.004

Zolina, O., Simmer, C., Belyaev, K., Kapala, A. and Gulev, S., 2009. Improving estimates of heavy and extreme pre- cipitation using daily records from European Rain Gauges. J Hydrometeorol, 10, 701-716.

Manuscript received 14 Mar., 2014, revised and accepted 29 Oct., 2014. 